\title{
From Earth to Outer Space: Laser cleaning semiprecious quartz and a novel application for meteoritic metal
}

\author{
Rebecca A. Kaczkowski ${ }^{1 \star}$, Bartosz A. Dajnowski ${ }^{2}$, Edward P. Vicenzi ${ }^{1}$ \\ 1 Museum Conservation Institute, Smithsonian Institution, 4210 Silver Hill Road, MRC 534, \\ Suitland, MD 20746, USA \\ 2 Conservation of Sculpture and Objects Studio, Inc., 900 S. Des Plaines Ave, Forest Park, \\ IL 60130, USA \\ * Corresponding author: KaczkowskiR@si.edu
}

\begin{abstract}
Varying the pulse duration, pulse frequency, and fluence (energy density) of conservation lasers can result in successful cleaning of mineralogical materials such as quartz crystals coated with iron oxide films and corroded iron meteorites. Semiprecious quartz is valued by specimen collectors for its euhedral crystal habit and is desirable for commercial applications given its uniform piezo-electric properties. Infrared laser pulses may provide a rapid means for removing metal oxide films from these rough crystals. Extraterrestrial minerals within meteorites provide scientists with valuable information about the origin of our solar system, as well as geologic events in the Earth's deep history. Iron meteorite samples are typically mechanically sectioned and polished to reveal crystalline structures displayed in reflected light microscopy. However, the surfaces of these iron-rich samples can easily oxidize when exposed to moisture and other environmental contaminants. Wet polishing methods, inappropriate handling, and atmospheric exposure can therefore result in surface corrosion in the form of iron oxy-hydroxide-hydrates (e.g. goethite and lepidocrocite). Further hydroxyl and chlorine uptake leads to formation of akaganéite $\left(\mathrm{Fe}^{3+} \mathrm{O}(\mathrm{OH}, \mathrm{Cl})\right)$. The use of $1064 \mathrm{~nm}$ laser pulses at various durations and fluences, in both atmospheric conditions and aided by an argon purge, is explored in this study as a means to remove the corrosion products from an iron meteorite. This method avoids the removal of a significant mass of specimen material involved with grinding and polishing, without the introduction of additional exposure to water. Effects of laser treatment were monitored using scanning electron microscopy and energy dispersive x-ray spectrometry (SEM-EDS). The SEM-EDS "postmortem" evaluation of corrosion removal from iron meteorites establishes the nature of the specimen surface chemistry and morphology following laser cleaning.
\end{abstract}

Keywords: high frequency laser cleaning, minerals, meteorite, natural history conservation, quartz, FeNi alloy

\section{Introduction}

At its core, natural science conservation is dedicated to preserving the scientific utility of the specimens within museum collections. Retaining physical evidence in a specimen allows scientists to weigh theory against observations. Specimens collected for research undergo various preparation techniques to enhance their scientific utility 
for a specific purpose, but each preparation technique can deleteriously impact that same usefulness to answer other, currently unanticipated hypotheses. Thus, collection staff have the challenging task to retain as much chemical, molecular, and physical integrity in the specimens held in museum collections as possible; this includes modifications induced by the initial preparation methodology, subsequent conservation treatment, storage, exhibition, and even analyses. For conservation treatment methodology to be adopted in a natural science context, it must be efficient, effective, and instigate the least amount of chemical or physical change in a material. For these reasons, a study to evaluate the feasibility of incorporating laser cleaning techniques, which can be markedly more efficient and non-destructive than traditional techniques, into the conservation treatment of mineralogical specimens was developed.

This study draws on previous work related to laser cleaning of iron alloys and quartz-containing matrices with a high-frequency system $[1,2]$; there are few published natural history-related investigations into the use of laser cleaning as a conservation tool to remove museum-applied coatings and efflorescence or as a preparation tool to enhance the utility of the specimen such as removal of matrix from fossilized bone [3-7]. In other studies involving iron alloys and quartz-containing stone matrices, laser cleaning at $1064 \mathrm{~nm}$ proved an effective tool to reduce corrosion and weathering products, respectively. The cleaning of iron alloys has been shown to be achievable at low fluences and even at slightly higher fluences with the addition of moisture or ethanol, while the formation of oxides and damage to the alloy can also easily occur [8-10]. Changing these laser parameters ultimately influences the relationships between the possible photomechanical, photochemical, and photothermal effects of the ablation process on the surface of the material. For example, shorter pulses can have more peak energy than longer pulses, and therefore can generate greater photoacoustic shock. Whereas longer pulses tend to generate less photoacoustic shock while having more plasma formation and more potential for photothermal effects [11]. The first part of this study focuses on the interaction of the laser beam with a relatively simple matrix to remove a thin coating formed in a geological setting: specifically, quartz $\left(\mathrm{SiO}_{2}\right)$ provides an excellent substrate to monitor the efficacy of the laser in removing an iron-oxide film. Post-cleaning evaluation of these laser cleaned surfaces using SEM-EDS was deemed a necessary step prior to approaching more chemically complex materials, such as corrosion from an iron meteorite, in the second part of this study.

\subsection{Iron Meteorites in Collections}

A meteorite is a fragment of extraterrestrial material that enters Earth's atmosphere and impacts our planet's surface. Most specimens represent material from the early solar system and reveal a host of processes related to planetary formation. Meteorites range from stony (chondrites and achondrites), to stony-iron, to iron [12]. Some of the greatest preservation challenges persist in the iron meteorite group, and an example metal corrosion issue is the focus of this study. The iron group is composed of predominantly iron-nickel alloys in two primary cubic metallic minerals: kamacite $(\alpha-(\mathrm{Fe}, \mathrm{Ni}) ; 5-12$ wt $\% \mathrm{Ni})$ and taenite $(\gamma-(\mathrm{Ni}, \mathrm{Fe}) ; 20-65 \% \mathrm{wt} \%$ 
$\mathrm{Ni})$. While iron and nickel comprise the most abundant elements in iron meteorites, phosphorous, sulphur, carbon, and silicon account for the remaining fraction of their chemical make-up.

Chlorine is a terrestrial contaminant derived from aqueous and atmospheric sources that threatens the stability of all iron meteorites buried in soil or water-saturated sediment $[12,13]$. The primary chlorine-bearing iron corrosion product formed is akaganéite, an iron III oxyhydroxide [14-16]. Akaganéite $(\beta-\mathrm{FeO}(\mathrm{OH}))$ is poorly ordered, and its small crystal sizes have a high capacity to take on moisture readily in ambient conditions $[15,17]$. The resulting corrosion products have a molar volume of approximately three times greater than the primary meteorite minerals, causing devastating losses to the specimen by way of cracks and exfoliation if left unchecked $[12,13,17]$. Chlorine ions are highly mobile in akaganéite, and the mineral can decompose in situ to intergrowths of goethite $(\gamma-\mathrm{FeO}(\mathrm{OH}))$ and maghemite $\left(\gamma-\mathrm{Fe}_{2} \mathrm{O}_{3}\right)$ or nickeliferous maghemite $[13,14,17,18]$.

The typical means for specimen preparation of iron meteorites includes diamond sawing followed by polishing; some samples can then be prepared as polished thick sections embedded in resin for transmitted light examination. Removing corrosion products often involves similar cutting and grinding methods. Because metallurgical changes can occur in iron meteorites at a few hundred degrees Celsius, so the use of a lubricant during cutting is used to mitigate frictional heating [12]. Cutting and polishing can add additional moisture to the system and can serve to exacerbate corrosion in chlorine-contaminated specimens. Additionally, polishing irreversibly removes bulk material from the specimen, compounding mass lost to corrosion. Although this removal of material from the specimen is minor, this can represent significant loss of material for a polished thin section.

Similar to the conservation of other iron-rich artifacts, e.g. archaeological objects, the removal or reduction of chlorine ions from the bulk of the material is necessary to mitigate the potential for future corrosion in moderate storage environments that do not rely on actively monitored hypoxic conditions $[13,19]$. The soluble nature of some chlorine species in iron and the knowledge of chlorine's role in corrosion has led to the development of desalination treatments; however, this process is difficult to monitor to an end point and is not fully effective in the complete removal of the chlorine contaminant. Experimental hydrogen plasma treatments have also been explored as a means both for iron species reduction (at low temperatures, $<150^{\circ} \mathrm{C}$ ) to facilitate corrosion removal and for chlorine extraction (at high temperatures, $>300-400^{\circ} \mathrm{C}$ ) [17-19]. The primary drawback of the process is that high temperatures in excess of $400-700^{\circ} \mathrm{C}$ are required for directly extracting chlorine contamination from the bulk of the iron meteorite, while temperatures as low as $250^{\circ} \mathrm{C}$ can result in micro-fracturing of the crystal structure. Micro-fracturing facilitates continued corrosion and subsequent loss of scientific integrity of the specimen $[17,20]$. Low temperature plasma cleaning does not impart metallurgical changes in the metal substrate, however chlorine is not directly extracted through this method. Follow-up mechanical and aqueous processes are required, demanding interventive and time-consuming treatment [18]. 


\section{Materials and Methods}

\subsection{Sample Materials and Preparation}

The first sample laser cleaned in this study was quartz mined from the Ouachita Mountains of Arkansas (Fig. 1).

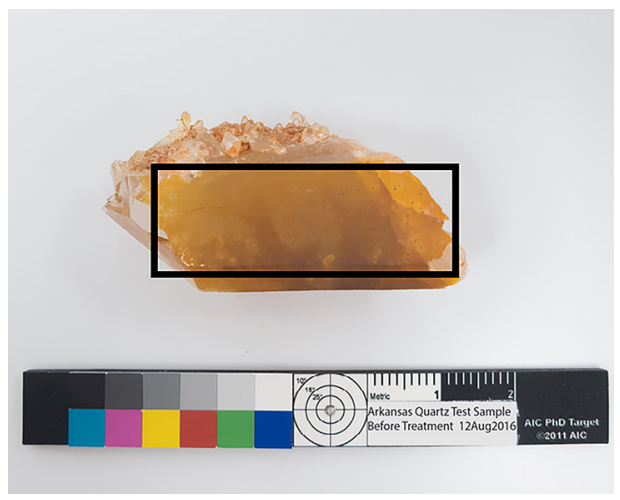

Fig. 1. Growth face of Arkansas quartz used for test cleaning, prior to treatment; region of interest is outlined in black rectangle.

The specimen was extracted by hand and was encapsulated in iron-rich clay; the clay was removed via rinsing with water. The quartz exhibited a thin iron oxide film/ deposit on the interface between the surface of the quartz and the surrounding matrix material. A thin film estimated to be less than $10 \mu \mathrm{m}$ thick determined from Hirox 3-D digital microscopy, the iron oxide coating was well bound to the surface of the crystal. Mechanical removal was, therefore, nearly impossible given the 3-D nature of the crystal growth surfaces and inefficient without marring the surfaces. Cleaning procedures used by mineral collectors include the mechanical reduction of all matrix material followed by immersion in an acidic solution with gradual heating to just below the boiling point for at least 8 hours, followed by a gradual cooling period to room temperature, and a final rinse with pure water to remove acidic residues.
Rapid temperature changes are avoided to prevent thermal shock and cracking of the crystal. A common recipe among quartz miners in Arkansas for preparing this acid bath is to use approximately $0.11 \mathrm{~kg}(0.25$ lbs.) of oxalic acid powder for every 3.8 liters (1.0 gallon) of water. Due to the hazardous fumes produced in the process, these acidic solutions are often cooked outdoors in containers over a heat source such as fire. Alternatively, rock collectors often use pressure cookers to heat the acid bath. For the purposes of this study, a large growth face of a single quartz crystal measuring roughly $3.0 \mathrm{~cm} \times 1.0 \mathrm{~cm}$ was selected due to the relative uniformity of the iron oxide film, in addition to ample surface area available for test cleaning. In an effort to gauge cleaning efficacy of traditional acid cleaning versus laser cleaning, an approximate $1.0 \mathrm{~cm} \times 0.5$ $\mathrm{cm}$ portion of the sample was removed by a water-cooled, low-speed diamond saw for acid cleaning. The remainder of the test face of the sample was masked into a grid-like pattern for laser cleaning tests. The masking material consisted of aluminum foil for aqueous cleaning and heavy white cardstock for cleaning in atmosphere.

The second sample utilized in this study was a $24.67 \mathrm{~g}$ cut, unpolished piece of Canyon Diablo (USNM 676), a well characterized iron meteorite (Fig. 2).

Canyon Diablo is the meteorite responsible for the geologically young ( 49 ka) impact crater in the southeastern United States, called Barringer Meteor Crater [21]. The sample was selected for its mineral phase chemistry and its presentation of typical corrosion found on similar irons stored in zip-top polyethylene bags within powder-coated stainless steel museum storage cases. Designated an iron meteorite class IAB-MG, Canyon Diablo is a coarse-grained 


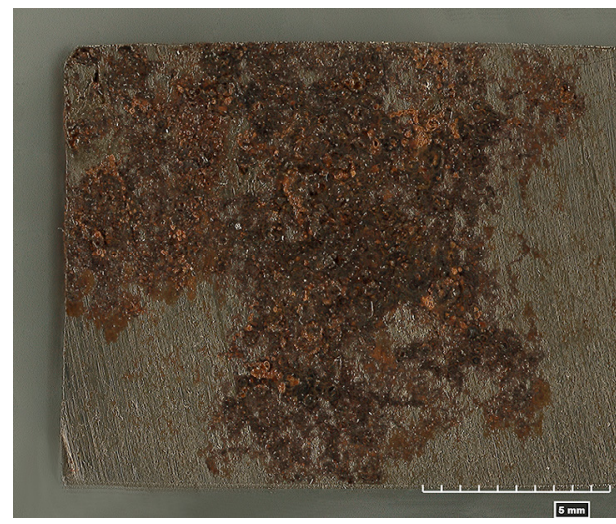

Fig. 2. Photomicrograph of iron meteorite sample (USNM 676), sawed and corroded surface used for laser test cleaning, prior to treatment; whole scale represents $5 \mathrm{~mm}$.

octahedrite. Kamacite ( $\alpha-(\mathrm{Fe}, \mathrm{Ni}) ; 5-12 \mathrm{wt} \%$ $\mathrm{Ni})$ and taenite $(\gamma-(\mathrm{Ni}, \mathrm{Fe}) ; 20-65 \% \mathrm{wt} \% \mathrm{Ni})$ comprise the majority of the volume, with minor schreibersite $\left((\mathrm{Fe}, \mathrm{Ni})_{3} \mathrm{P}\right)$ confirmed by SEM-EDS imaging and analysis. In addition to primary minerals kamacite, taenite, and schreibersite, chlorine was detected in significant concentration in association with the corroded surface and secondary mineralization (Fig. 3, Tab. 1).

Table 1. Semi-Quantitative Elemental Analysis of Meteorite Corrosion

\begin{tabular}{lcc}
\hline Element & Weight (\%) & Atomic (\%) \\
\hline Iron $(\mathrm{Fe})$ & 48.6 & 20.8 \\
Oxygen $(\mathrm{O})$ & 34.6 & 51.7 \\
Carbon $(\mathrm{C})$ & 12.7 & 25.3 \\
Chlorine $(\mathrm{Cl})$ & 2.4 & 1.6 \\
Nickel $(\mathrm{Ni})$ & 1.6 & 0.7 \\
\hline Total & 99.9 & 100 \\
\hline
\end{tabular}

Similar to the quartz sample, the largest area of corrosion on the meteorite sample surface was masked into a grid for laser cleaning tests. Masking material consisted of heavy white cardstock, cut with a $2 \times 3$ grid of $0.5 \mathrm{~cm}^{2}$ squares. To ensure the mask achieved

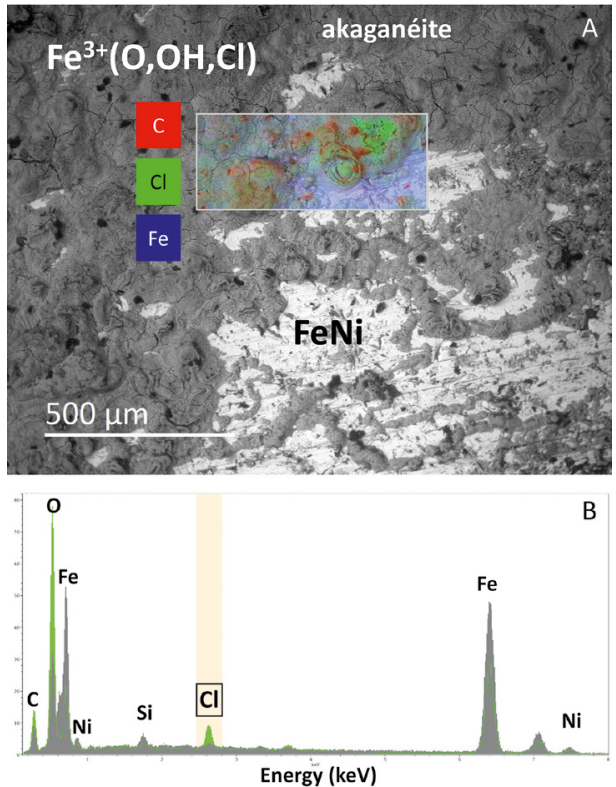

Fig. 3. (A) Backscattered electron image of corrosion on the iron-nickel alloy surface (USNM 676) with a false-color chemical image overlay (carbon, red; chlorine, green; iron, blue), prior to treatment and (B) X-ray spectrum for non-corroded iron- nickel surface (grey) and the chlorine-rich region of corrosion (blue), prior to treatment.

sufficient contact with the sample surface and no ejected material would impact other sample sites, a rare earth magnet secured the grid and mask to the sample.

\subsection{Cleaning Procedures}

All laser cleaning tests were carried out with a state-of-the-art 70-watt, solid-state, high frequency $(10 \mathrm{kHz}-1 \mathrm{MHz})$ conservation laser operating at $1064 \mathrm{~nm}$ [22]. For this setup, the laser had an in-focus spot size of 250 $\mu \mathrm{m}$ when using a $16.0 \mathrm{~cm}$ focal lens; this value was confirmed by measuring a test area on carbon laser paper with the Hirox microscope. The high-frequency pulses of 
the beam are delivered via fiber optic cable to a scanning head that emits a unique circular scan pattern with a conical delivery path that allows the beam to interact with the surface from various angles as the leading edge and trailing edge of the scan move across the object. This optical configuration allows for the scan to conform to shapes and crevices while providing multiple exposures per pass. The continuous path of the circle scan helps ensure that the pulses do not linger in one place for too long. The desired pulse overlap pattern and cleaning speed is determined by the laser parameters and technique employed by the operator. The circular scan pattern used in this experiment measured 2.0 $\mathrm{cm}$ in diameter. Multiple parameters were manipulated during test cleaning to achieve the differing cleaning levels, including pulse energy, pulse duration, pulse frequency, and revolutions per minute (RPM) of the scan. Although a wide range of pulse durations was available to test, in order to maximize the potential for repeatability by others in the field, the most commonly used pulse durations of $10 \mathrm{~ns}$ and $100 \mathrm{~ns}$ were selected.

Test cleaning of quartz was carried out under two environmental conditions: with the specimen submerged underwater, and in ambient conservation laboratory conditions, assisted by the aid of an extraction trunk located approximately $15.0 \mathrm{~cm}$ from the test cleaning site. The former cleaning scenario was used in an effort to increase the efficiency of laser cleaning by reducing potential redeposition of ablated material. Water is commonly used during laser cleaning protocols for benefits such as the added micro-steam-cleaning effect when water is vaporized by laser pulses; additionally, water does not act as a solvent to the contaminant layer and interfere with evaluation of the laser cleaning efficacy. In order to mini- mize the reduction of the fluence of pulses reaching the surface of the crystal due to water absorption of energy, the crystal was submerged only a few millimeters below the surface. For test cleaning carried out in ambient conditions, the specimen was propped at an approximately $40^{\circ}$ angle on a glass stand with white cardstock masking off all areas not to be exposed to the laser energy. Cleaning at the selected parameters was carried out by making 2-3 passes across the test site, moving the scan manually at approximately $1 \mathrm{~cm}$ per second, both vertically and horizontally to ensure equal exposure and achieve the desired aesthetic clean. Unlike low frequency lasers that are commonly used with larger spot sizes, measured in millimeters, and higher pulse energies, a scanning system like this one uses hundreds of thousands of weaker pulses, measured in microns, to allow for even and gentle cleaning. The masks were removed between cleaning tests to evaluate cleaning levels (Tab. 2). For cleaning tests performed with the specimen submerged underwater, the specimen was wrapped in aluminum foil and the test site "windows" were cut out of the foil. An additional foil mask was used across the surface of the specimen to ensure that only one window was exposed to laser energy at a time (Fig. 4).

The sample was then placed on a glass stand in a glass bowl of deionized water. Cleaning at the selected parameters was carried out in a similar manner as before. This procedure produced nearly equal laser exposure and achieved the desired level of cleaning as determined visually.

Test cleaning of the iron meteorite was also carried out in two environmental conditions: the same ambient conservation laboratory conditions as the quartz, and with an argon purge delivered via plastic nozzle at $180 \mathrm{psi}$ with an extraction trunk. The argon purge 
Table 2. Cleaning Parameters per Test Site on Quartz

\begin{tabular}{clcccc}
\hline $\begin{array}{c}\text { Test } \\
\text { Site }\end{array}$ & Environment & $\begin{array}{c}\text { Pulse duration } \\
(\mathrm{ns})\end{array}$ & $\begin{array}{c}\text { Frequency } \\
(\mathrm{KHz})\end{array}$ & $\begin{array}{c}\text { Frequency of } \\
\text { rotation }(\mathrm{RPM})\end{array}$ & $\begin{array}{c}\text { Fluence } \\
\left(\mathrm{J} / \mathrm{cm}^{2}\right)\end{array}$ \\
\hline 1 & Ambient & 250 & 50 & 8,000 & 2.65 \\
2 & Ambient & 10 & 450 & 8,000 & 0.30 \\
3 & Ambient & 50 & 150 & 8,000 & 0.88 \\
4 & Ambient & 80 & 150 & 8,000 & 0.94 \\
5 & Ambient & 150 & 150 & 8,000 & 0.96 \\
6 & Ambient & 250 & 150 & 8,000 & 0.97 \\
7 & Ambient & 250 & 50 & 3,000 & 2.65 \\
8 & Ambient & 250 & 50 & 3,000 & 2.65 \\
9 & Ambient & 250 & 50 & 3,000 & 2.65 \\
10 & Under Water & 250 & 50 & 8,000 & 2.65 \\
11 & Under Water & 250 & 50 & 3,000 & 2.65 \\
12 & Under Water & 10 & 450 & 8,000 & 0.30 \\
13 & Under Water & 50 & 150 & 8,000 & 1.03 \\
14 & Under Water & 80 & 150 & 8,000 & 0.94 \\
15 & Under Water & 150 & 150 & 8,000 & 0.96 \\
16 & Under Water & 250 & 150 & 8,000 & 0.97 \\
\hline
\end{tabular}

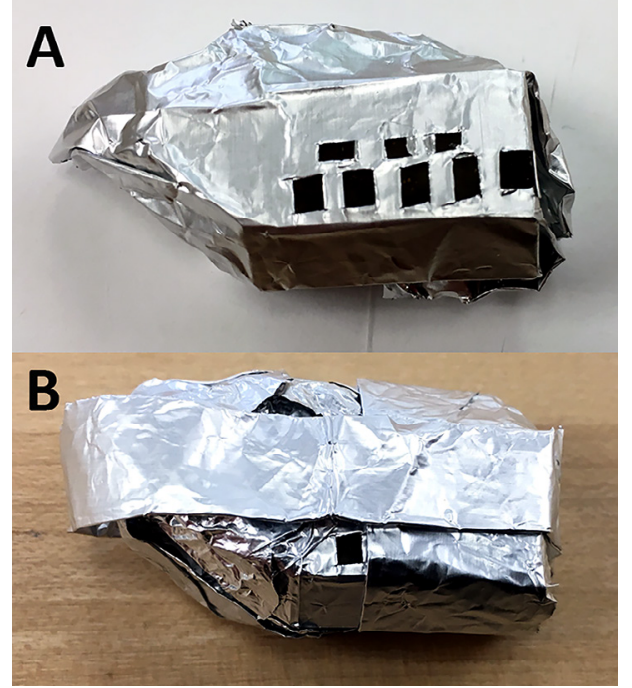

Fig. 4. (A) Quartz sample masked with aluminum foil and (B) quartz sample with the additional aluminum-foil mask for underwater laser cleaning. was used to promote heat dissipation and hinder oxide formation on the metal surface. The sample was propped at a $45^{\circ}$ angle on a glass stand. To have the largest area possible for test cleaning with the limited concentration of corrosion on the surface, six test sites measuring $5.0 \mathrm{~mm}^{2}$ each were masked in heavy white cardstock: three sites for ambient environmental conditions with differing fluences and pulse durations $\left(0.23 \mathrm{~J} / \mathrm{cm}^{2} @\right.$ $10 \mathrm{~ns}, 0.31 \mathrm{~J} / \mathrm{cm}^{2} @ 100 \mathrm{~ns}$, and $1.0 \mathrm{~J} / \mathrm{cm}^{2} @$ 100 ns, respectively), and three for the same fluences with an argon purge. Using two rare earth magnets to hold the heavy white cardstock ensured sufficient contact of the mask to the sample. At each test cleaning site, $2-3$ passes by the conservator with the high-frequency laser were made across the test site both vertically and horizontally in an effort to achieve nearly equal laser exposure. These conditions produced a suitable level of cleaning based upon visual inspection. Masks were removed between cleaning tests to evaluate cleaning levels (Tab. 3). 
Table 3. Cleaning Parameters per Test Site on Iron Meteorite (USNM 676)

\begin{tabular}{clcccc}
\hline $\begin{array}{c}\text { Test } \\
\text { Site }\end{array}$ & Environment & $\begin{array}{c}\text { Pulse duration } \\
(\mathrm{ns})\end{array}$ & $\begin{array}{c}\text { Frequency } \\
(\mathrm{KHz})\end{array}$ & $\begin{array}{c}\text { Frequency of } \\
\text { rotation }(\mathrm{RPM})\end{array}$ & $\begin{array}{c}\text { Fluence } \\
\left(\mathrm{J} / \mathrm{cm}^{2}\right)\end{array}$ \\
\hline A1 & Ambient & 10 & 400 & 8,000 & 0.23 \\
A2 & Argon & 10 & 400 & 8,000 & 0.23 \\
A3 & Ambient & 100 & 400 & 8,000 & 0.31 \\
A4 & Argon & 100 & 400 & 8,000 & 0.31 \\
A5 & Ambient & 100 & 100 & 8,000 & 1.0 \\
A6 & Argon & 100 & 100 & 8,000 & 1.0 \\
\hline
\end{tabular}

\subsection{Documentation and Analysis}

The surfaces of both the quartz and iron meteorite samples were documented prior to, and following laser experiments. Contamination layers were also characterized via visible light and scanning electron microscopy methods outlined below.

Optical microscopy (Hirox KH-8700 with MGX-2500REZ and MGX-1260 lenses with variable lighting attachment) was performed on both the quartz and iron meteorite samples to characterize the thickness of the contamination layers, the nature of the substrates, and to monitor cleaning. Using the variable lighting adapter that employs a rotating mirror to direct the light to the sample, surfaces were observed with the light at $25^{\circ}, 55^{\circ}$, and $75^{\circ}$ angles, highlighting surface non-uniformity and residues.

Scanning electron microscopy with energy dispersive $\mathrm{x}$-ray spectrometry (Hitachi S-3700N, operating at $100 \mathrm{~Pa}$ atmosphere variable pressure for uncoated samples, 15-20 kV, with a Bruker XFlash 4010 detector using a pulse time constant of $1.25 \mu \mathrm{s}$ ) was used to characterize the surfaces of the samples before and after cleaning tests. SEMEDS output documented the morphological and elemental composition of substrates and corrosion products. These results provided an evaluation of relative contaminant concentration before and after test cleaning.
X-ray diffraction (Rigaku D/MAXRAPID XRD) was carried out for corrosion material scraped from the iron meteorite to determine its mineralogical content. An approximately 800 micron thick sample was manually removed from an area of dense corrosion adjacent to the laser testing sites with a scalpel performed at low magnification using a stereomicroscope. The sample was then adhered to a glass fiber with Elmer's glue (PVA emulsion) and exposed to $\mathrm{Cu}$ radiation for 60 minutes using a 300 micron collimator. No discernable diffraction pattern was obtained. This result is likely due to the poor crystallinity of the iron corrosion products.

\section{Cleaning Results and Discussion}

\subsection{Quartz}

Preliminary results show that cleaning tests in ambient conservation laboratory conditions produced macroscopically clean quartz. Cleaning was stopped when the quartz appeared clean to the naked eye. Optical microscopy with coaxial $25^{\circ}$ angle lighting, however, reveals a regular pattern of cleaned circles within an incompletely cleaned field of iron oxide film (Fig. 5).

EDS mapping of the cleaned areas reveals that the diameter of the cleaned circles is roughly $10.0 \mu \mathrm{m}$ and an iron-rich residue is 


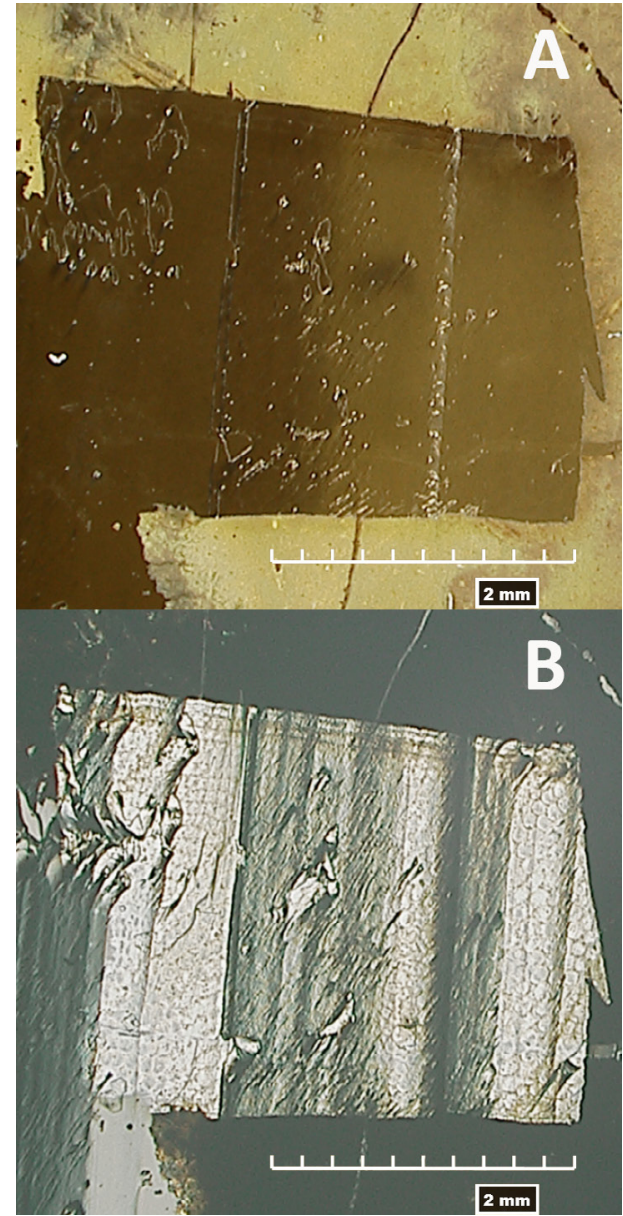

Fig. 5. (A) Spot $1\left(\mathrm{~F}=2.65 \mathrm{~J} / \mathrm{cm}^{2}\right)$ appears clean with ring lighting and (B) Spot 1 under coaxial lighting conditions reveals surface patterning of thin-film residue; whole scales represent $2 \mathrm{~mm}$

left in the areas around the circles (Fig. 6). The circular scan pattern of the beam delivery at $50 \mathrm{kHz}$ and 8,000 RPM allows for significant overlap of each pulse; the residue pattern is inconsistent with this overlap. Furthermore, the fiber-optically delivered beam spot from the laser is $250 \mu \mathrm{m}$ in diameter with the 16 $\mathrm{cm}$ focal lens used in this study, as confirmed by measuring a test area on carbon laser paper with the Hirox microscope. The reason

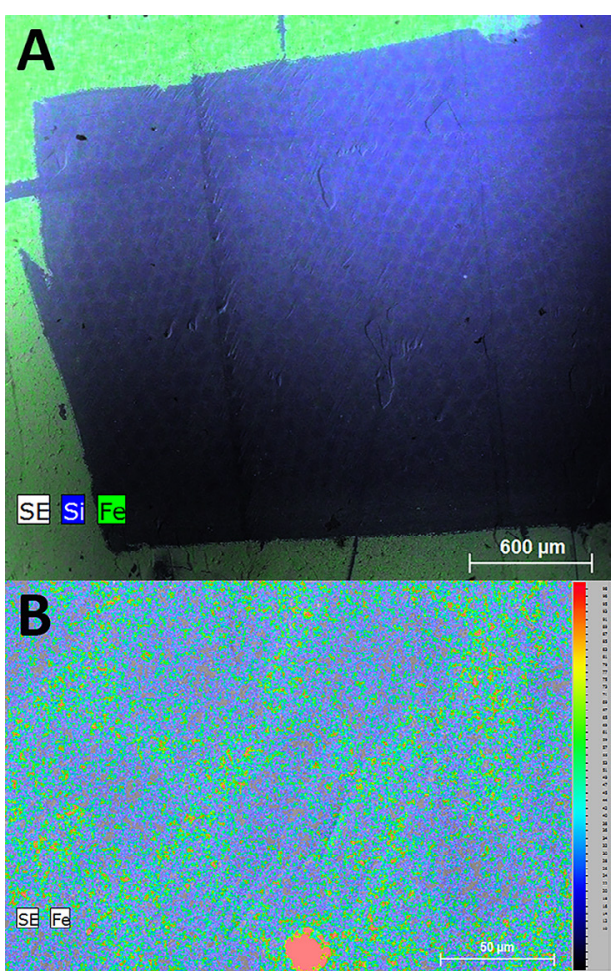

Fig. 6. (A) Secondary electron image with false-color overlay for silicon (blue) and iron (green). There is a residue pattern within spot $1\left(\mathrm{~F}=2.65 \mathrm{~J} / \mathrm{cm}^{2}\right)$ and (B) the log of the intensity (rainbow false color) of $\mathrm{Fe} \mathrm{K}_{a}$ within the only area of significant iron enrichment on the laser-cleaned region of Spot 1; scale in Fig. B represents $50 \mu \mathrm{m}$.

for the residue pattern is not readily apparent considering the instrumentation parameters used. It is unclear if the residue is a result of under cleaning or redeposition of material. It is possible that the $16 \mathrm{~cm}$ focal lens that was used had a contaminant or an optical aberration, or, that additional optical phenomena are occurring as a result of the unique linear and nonlinear optical properties of quartz to create this pattern.

It is also important to note that the quartz is transmissive of $1064 \mathrm{~nm}$ laser pulses, and a cleaning effect on the opposite growth face 
to the cleaning site was also observed. No specific damage to the surface of the crystal was noted, however. Rather, the imperfect surface of the crystal growth face is revealed by the cleaning process. The quartz was not exposed to additional laser pulses after the residue was discovered. It was not tested if additional exposure to more pulses at the same parameters or pulses at other laser parameters would remove the remaining res-

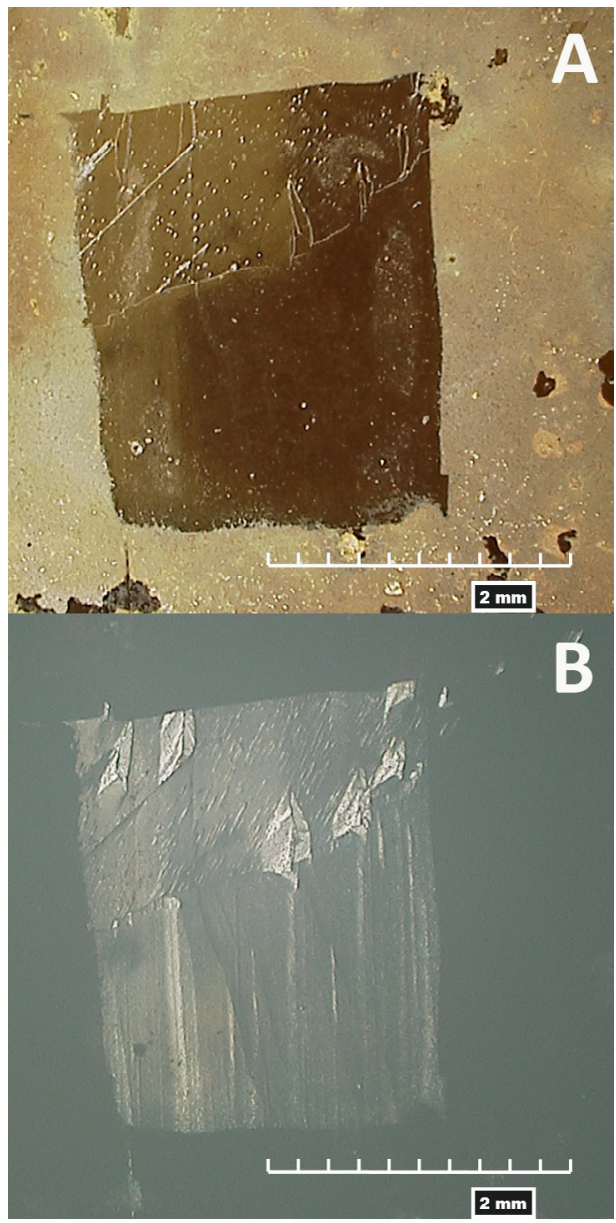

Fig. 7. (A) Spot $10\left(\mathrm{~F}=2.65 \mathrm{~J} / \mathrm{cm}^{2}\right)$ appears clean with ring lighting, and (B) Spot 10 under coaxial lighting conditions reveals no distinct surface patterning of thin-film residue. idue that was revealed with coaxial lighting optical microscopy and EDS.

Cleaning tests performed under water also produced macroscopically clean quartz. Light microscopy revealed no post-cleaning pattern observed in the previous cleaning tests (Fig. 7, 8).

Residual iron oxide film does, however, remain on the surface, as observed through EDS mapping of the cleaned areas. The

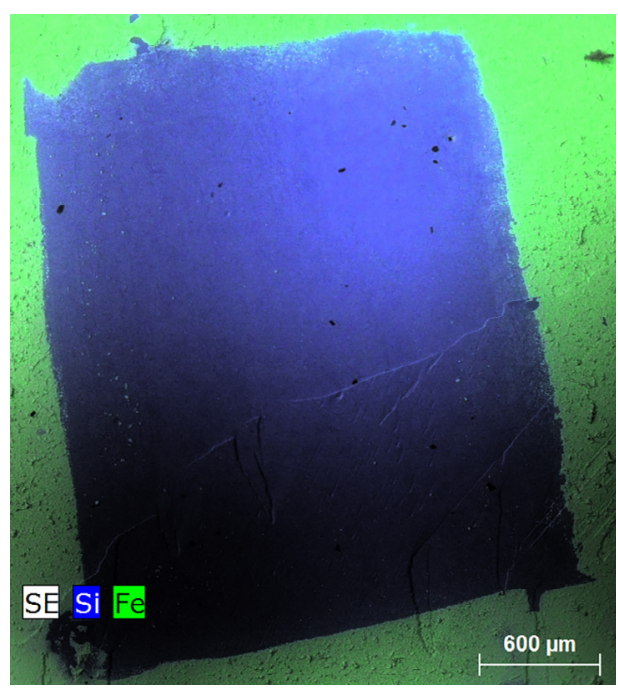

Fig. 8. Secondary electron image with false-color overlay for silicon (blue) and iron (green). There is no residue pattern within spot $10\left(\mathrm{~F}=2.65 \mathrm{~J} / \mathrm{cm}^{2}\right)$.

cleaning effect observed on the opposite growth face to the cleaning site was divested of less material than the test areas cleaned in ambient conditions; this is a result of the energy absorbance of water.

Again, no specific damage to the surface of the crystal is noted however, and the crystal growth-face imperfections are revealed.

On a microscopic scale, oxalic acid cleaning of quartz appears more complete, relative to the laser conditions employed in this study. Although the laser energy did not show 
deleterious effects to the crystal, the oxalic acid method achieved a more completely clean surface. Iron was detectable on the acid-cleaned sample in SEM-EDS (Fig. 9).

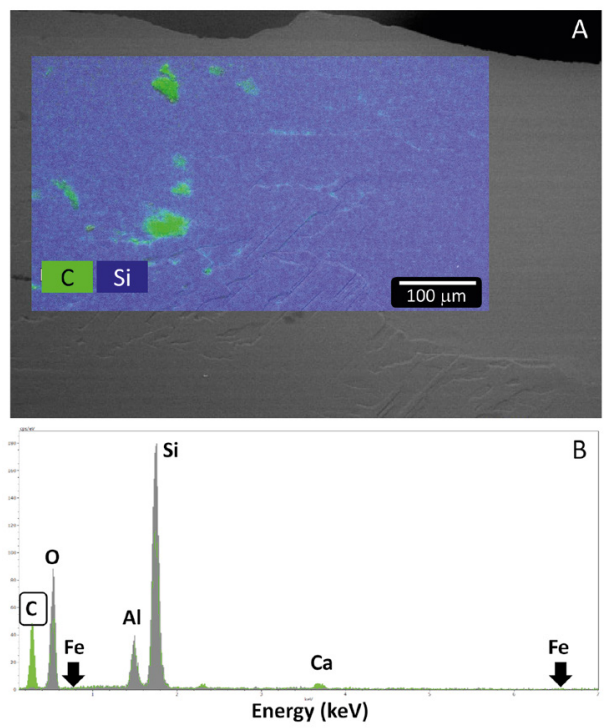

Fig. 9. (A) Backscatter scanning electron image with elemental false-color overlay (silicon, blue; carbon, green), and (B) X-ray spectrum of a carbon-rich area from the same region of interest (green) and the surrounding cleaned area (grey) illustrates how localized carbon is on the surface as a discrete contaminant and iron is not present. However, carbon was detected in localized areas on the acid-cleaned quartz surface and appears to be associated with organic matter from the matrix (e.g. vegetation in the soil) that was not readily removed during treatment with oxalic acid.

\subsection{Meteorite}

Energy imparted by the laser partly removed corrosion products from all test sites of the Canyon Diablo specimen (Fig. 10).

Areas cleaned at a fluence of $0.23 \mathrm{~J} / \mathrm{cm}^{2}$ @ $10 \mathrm{~ns}$, appeared clean with an undisturbed metal substrate. However, the other four test sites cleaned with fluences of $0.31 \mathrm{~J} / \mathrm{cm}^{2} @$ $100 \mathrm{~ns}$ and $1.0 \mathrm{~J} / \mathrm{cm}^{2} @ 100 \mathrm{~ns}$, also appeared

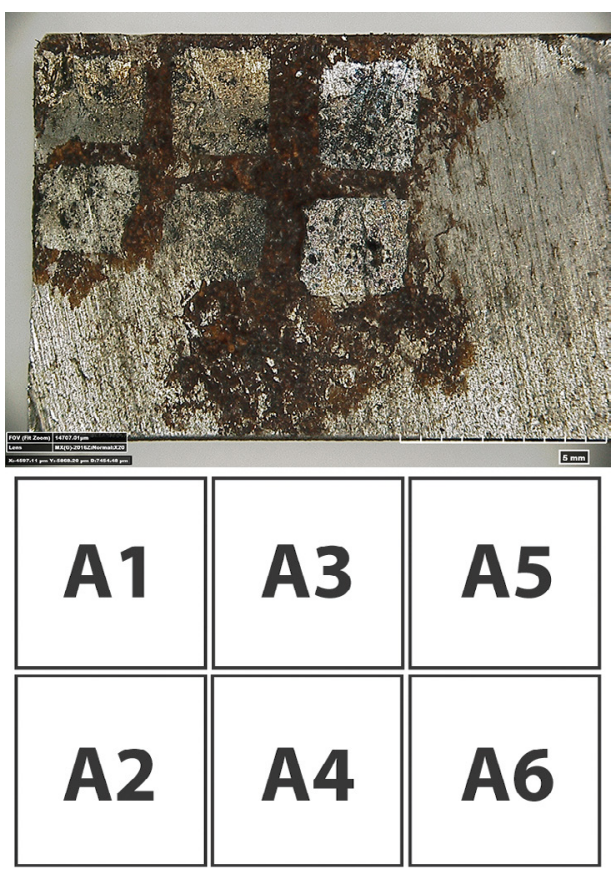

Fig. 10. Photomicrograph of iron meteorite (USNM 676), sawed and corroded surface used for laser test cleaning, after treatment; all test sites successfully removed corrosion products, albeit incompletely. A labeled diagram of the test sites is below.

cleaned, but the substrates were altered by the laser pulses. Additionally, a slight color change to the metal substrate in test areas cleaned in air, versus those cleaned with an argon purge was also noted. There may also be some thin film oxide formation on the metal surface when exposed to air under certain pulsed laser conditions. The argon purge appears to have provided a reducing environment during cleaning, or dissipated heat evolved during ablation through gaseous advection. The observed color differences may also be an artifact of a non-uniform corrosion layer revealing a differently corrosion-affected surface beneath. Further, SEM-EDS mapping illustrated that all of the test sites - those cleaned in air and those with 
an argon purge - exhibited an incompletely cleaned surface. This may be due to an insufficient amount of laser pulses being used to fully clean the surface, or may be caused by: 1) redeposition of ablated material, 2) incomplete ejection of heated corrosion products by the laser, or, 3) both mechanisms operating in tandem. The observed color of the surface metal can also be attributable to the incomplete nature of the cleaning.

Furthermore, the concentration of chlorine appears to be reduced on all sample sites. Comparing the compositional images of the kamacite cleaned with a fluence of $0.31 \mathrm{~J} / \mathrm{cm}^{2} @ 100 \mathrm{~ns}$ surface with an area of incompletely removed corrosion, chlorine is observed to have been removed to within the detection limit of $\mathrm{x}$-ray microanalysis in the laser-cleaned regions. However, chlorine is likely removed only to the depth that the laser energy penetrated the specimen, approximately several microns. In order to evaluate the efficacy of this treatment for chlorine removal, compositional analysis of a cross section is required to monitor the chemical depth profile for chlorine removal. Previous studies have determined that effective bulk chloride removal in iron alloys can only be achieved at temperatures in excess of $400^{\circ} \mathrm{C}[16,17]$. Therefore, given the surface sensitivity of laser cleaning, chloride removal is limited to the uppermost micrometers of the sample surface.

Using the lowest energy density of $0.23 \mathrm{~J} / \mathrm{cm}^{2} @ 10 \mathrm{~ns}$ at the interface of the corrosion layer and cleaned metal substrate, there is a narrow, only microns wide, intermediary boundary between the cleaned area and unaffected corrosion layers (Fig. 11).

Fragile microstructures within the corrosion in this zone are left intact. This suggests that the laser is, indeed, a high-precision tool for selective corrosion removal. Conversely,

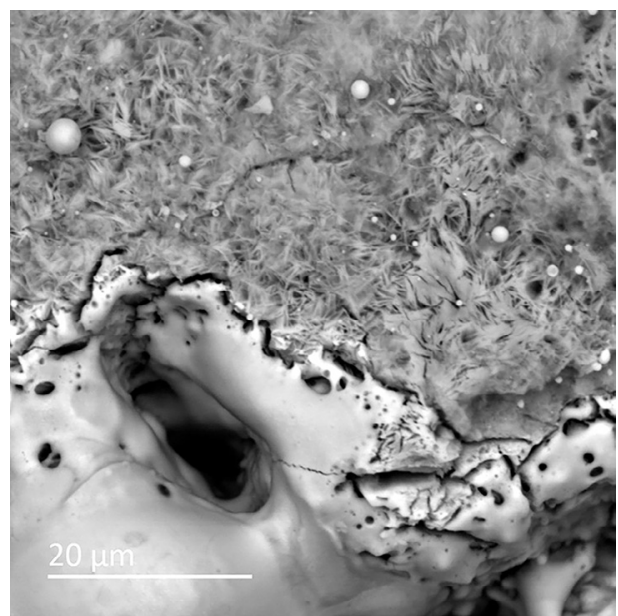

Fig. 11. Detail of the sharp boundary between laser-altered corrosion products and unaffected corrosion on Spot A1.

adjacent to areas of affected corrosion, cleaned but undamaged metal is revealed (Fig. 12). Redeposited spheres of corrosion are also visible on the surface.

At the same low fluence, but with the addition of an argon purge, the kamacite surface is similarly unaffected by the laser

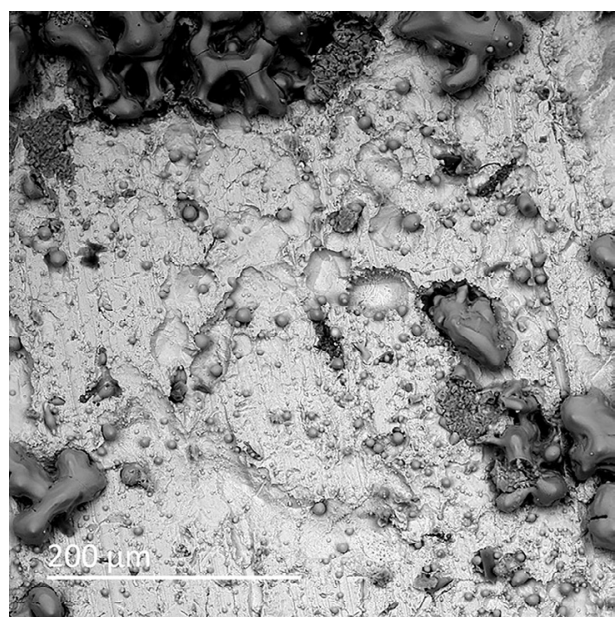

Fig. 12. Spot A1 is incompletely cleaned, but the metal substrate is unaltered by the lowest laser fluence $\left(0.23 \mathrm{~J} / \mathrm{cm}^{2}\right)$. 
energy - demonstrated by the crisp clarity of the shallow corrosion pits. Indeed, the incomplete ejection of corrosion from the surface and resultant formation of iron-oxide spheres is clear, as the corrosion products begin to curl inward toward the center of corrosion pits (Fig. 13). Smaller spheres may also be attributable to redeposition from the laser plume.

At the intermediate energy density used in this study, $0.31 \mathrm{~J} / \mathrm{cm}^{2} @ 100 \mathrm{~ns}$, observations under SEM-EDS revealed additional information related to the laser interaction with the substrate. Again the kamacite surface is unaffected by the laser energy, regardless of treatment in air or with the argon purge. Textural evidence for laser alteration was observed in the form of immiscibility between iron-nickel phosphate and iron-nickel-phosphide, an indication of their molten state during laser cleaning.

Although we have shown that the kamacite appears unaffected at a fluence of $0.23 \mathrm{~J} / \mathrm{cm}^{2}$

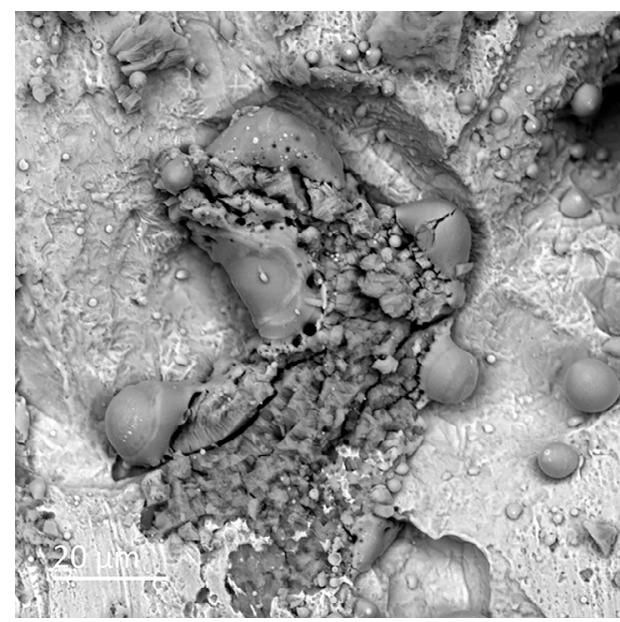

Fig. 13. Incipient melting of corrosion material to form anhydrous spherical particles of iron oxide masses; note the curling of the corrosion product inward from the edges of the pit.
@ $10 \mathrm{~ns}$ and $0.31 \mathrm{~J} / \mathrm{cm}^{2} @ 100 \mathrm{~ns}$, the latter fluence while cleaning in air is enough to preferentially affect the nickel-rich taenite. There was no evidence of taenite alteration on the argon-assisted cleaned area. Moreover, the damage threshold for the kamacite was also determined to be greater than $0.31 \mathrm{~J} / \mathrm{cm}^{2}$ @ $100 \mathrm{~ns}$, but less than $1.0 \mathrm{~J} / \mathrm{cm}^{2} @ 100 \mathrm{~ns}$, regardless of cleaning in air or with an argon purge. The lower damage threshold for the taenite versus the kamacite may be attributable to the mineral intergrowths within the taenite, resulting in a lower melting point of the material [23]; it may also be related to the grain size of the particular class of iron meteorite. A larger sampling of class IAB-MG iron meteorites with larger cleaning test sites is necessary to confirm this observation.

\section{Conclusions}

These initial findings indicate that it is possible to successfully remove iron oxide films from quartz with a high frequency tunable laser system. More testing is recommended to identify optimal parameters and conditions for cleaning quartz specimens. With a homogenous substrate such as quartz, the evaluation of laser cleaning efficacy is possible through SEM-EDS mapping of the treated areas before and after cleaning. It is also an effective tool for understanding the nature of the specimen surface chemistry and morphology following laser cleaning on more complex, heterogeneous samples, such as an iron meteorite.

From a macroscopic appraisal of the cleaned meteorite specimen, an ambient atmosphere coupled with the lowest fluence $\left(0.23 \mathrm{~J} / \mathrm{cm}^{2} @ 10 \mathrm{~ns}\right)$ produced a cleaned surface without affecting the substrate. Follow-up optical microscopy carried out in the 
NMNH's Department of Mineral Science, revealed cleaned areas at the lowest fluence did not have any detectable impact on the metallography. However, the incomplete nature of the laser cleaning required subsequent polishing of the sample for optical microscopy. Although high magnification examination of the test site found the cleaning to be incomplete, the aesthetic affect may be sufficient for non-research specimens or artifacts made of iron meteoritic metals. Cleaning was monitored macroscopically and terminated when the sample visually appeared to be clean; a more thorough cleaning may be possible with additional passes with laser pulses at these parameters, and/or through the incorporation of complementary cleaning techniques such as solvent methods.

Additionally, ranges for damage thresholds of the primary minerals taenite and kamacite were experimentally determined in this study. Taenite appears to have a lower relative damage threshold than kamacite. Neither taenite nor kamacite were affected by laser cleaning with a fluence of $0.23 \mathrm{~J} / \mathrm{cm}^{2}$ @ 10 ns. It should be noted, however, that determination of the damage threshold of the specimen or ablation threshold of the corrosion products were not the primary goals of this study. Rather, the study demonstrates that there are acceptable ranges of parameters to remove corrosion from the meteorite without adversely affecting the underlying substrate.

The effects of the laser observed at the argon-treated sites are believed to be the result of laser ablation under anoxic conditions, but have not been confirmed. From a macroscopic inspection, these sites have the appearance of a cleaner surface; however, the addition of the argon purge did not increase the damage threshold for either kamacite or taenite. A thin-film effect of what may be a native oxide patina appears to form on the samples treated under atmospheric conditions that was not readily observed with the argon-purge treated samples. This film is so thin that SEM-EDS is insufficiently sensitive with regard to chemical depth resolution, and requires a true surface technique, such as $\mathrm{x}$-ray photoelectron spectroscopy (XPS) to determine differences between samples treated in ambient atmosphere versus argon purge conditions.

Finally, the use of SEM-EDS proved to be an effective means for characterizing the surfaces of the samples and the contaminants, and also evaluating their subsequent changes as a result of cleaning treatments. Continued work to incorporate laser cleaning to reduce corrosion and chloride concentration on iron meteorites should employ complementary cleaning techniques already in practice in the treatment of meteorites. Laser cleaning may be able to fully remove corrosion products with proper parameters, or it could be used to successfully reduce the bulk of the surface corrosion, requiring subsequently less mechanical manipulation and polishing of the surface - and therefore less removal of the metal substrate. Only a few of the many possible laser parameter combinations were tested during this study, and these initial findings indicate that more in-depth and diversified experimentation with additional laser parameters is indeed worth exploring.

\section{Acknowledgements}

The authors would like to thank the following colleagues at the Museum Conservation Institute for their support and contributions to this research: Dr. Odile Madden, Dr. Gwénaëlle Kavich, Nicole Little, Dr. Thomas Lam, E. Keats Webb, Janet Douglas, Jessica Johnson, Dr. Robert Koestler, Dr. Paula 
DePriest. Additionally, this project would not have been possible without the support of colleagues in the Department of Mineral Sciences at the National Museum of Natural History: Dr. Timothy McCoy, Julie Hoskin, Timothy Gooding, and Timothy Rose. The authors are also immensely grateful to Dr. Andrzej Dajnowski for lending a GC-1 laser for use in this project and the guidance and support of Dr. Robert Waller, Catharine Hawks, and Marlene Yandrisevits.

\section{References}

[1] A. Dajnowski and B. Dajnowski, "A case study in the removal of paint and corrosion from cast iron using a Nd:YAG laser", in: Lasers in the Conservation of Artworks IX (Proceedings of LACONA IX conference), London, UK, September 7-10, 2011, D. Saunders, M. Strlič, C. Korenberg, N. Luxford, K. Birkhölzer (Eds.), Archetype Publications Ltd, London 2013, pp. 40-44.

[2] A. Dajnowski, "Laser cleaning of the Nickerson Mansion: The first building in the US entirely cleaned using laser ablation", in: Lasers in the Conservation of Artwork,s Proceedings of the International Conference LACONA VII, Madrid, Spain, September 17-21, 2007, J. Ruiz, R. Radvan, M. Oujja, M. Castillejo, P. Moreno (Eds.), CRC Press/Taylor \& Francis, London 2008, pp. 209-214.

[3] F. Landucci, R. Pini, S. Siano, R. Salimbeni, E. Pecchioni, "Laser Cleaning of Fossil Vertebrates: A Preliminary Report", Journal of Cultural Heritage, 1 (2000) S263-S267, DOI: 10.1016/S12962074(00)00141-2.

[4] F. Landucci, E. Pecchioni, D. Torre, P. Mazza, R. Pini, S. Siano, R. Salimbeni, "Toward an Optimsed Laser Cleaning Procedure to Treat Important Paleontological Specimens", Journal of Cultural Heritage, 4 (2003) 106s-110s. DOI: 10.1016/S12962074(02)01185-8.

[5] L. Cornish and C. G. Jones, "Laser Cleaning of Natural History Specimens and Subsequent SEM Examination", in: J. H. Townsend, K, Eremin, A. Adriaens (Eds.) Conservation Science 2002: Papers from the Conference Held in Edinburgh, Scotland, 22-24 May 2002, Archetype Publications Ltd, London 2003, pp. 101-106.
[6] E. Karantoni, E. Malea, N. A. Stefanis, A. Alexandropolou, K. Melessanaki, A. Selimis, P. Pouli, G. Panagiaris, "Studies on the Use of Laser Radiation to Clean Natural History Specimens: Preliminary Results", Poster number 1206 presented at the $17^{\text {th }}$ Triennial Conference of the International Council of Museums Committee for Conservation (ICOM-CC), Melbourne, Australia, 15-19 September 2014, (Proceedings in press).

[7] J. Asmus, "Laser conservation paleontology", Proceedings of SPIE 4402 (2001) 1-7, DOI: 0277786X/01/\$15.00.

[8] K. Dickmann, J. Hildenhagen, J. Studer, E. Musch, "Archaeological ironwork: Removal of corrosion layers by Nd:YAG-laser", in: Lasers in the Conservation of Artworks $V$ (Proceedings of the LACONA V conference), Osnabruck, Germany, September 15-18, 2003, K. Dickmann, C. Fotakis, and J. F. Asmus (Eds.), Springer-Verlag, Berlin 2005, pp. 71-77.

[9] C. Fotakis, D. Anglos, V. Zafiropulos, S. Georgiou, V. Tornari, Lasers in the Preservation of Cultural Heritage: Principles and Applications, Taylor \& Francis, New York 2007, pp. 306-313.

[10] C. Korenberg and A. M. Baldwin, "Laser cleaning of iron: Surface appearance and re-corrosion of model systems", in: Lasers in the Conservation of Artworks VIII (Proceedings of the LACONA VIII conference), Sibiu, Romania, September 21-25, 2009, R. Radvan, J. F. Asmus, M. Castillejo, P. Pouli, and A. Nevin (Eds.), CRC Press, Boca Raton, 2011, pp. 123-133.

[11] S. Siano and R. Salimbeni, "Advances in laser cleaning of artwork and objects of historical interest: The optimized pulse duration approach", Accounts of Chemical Research 43 (2010) 739-750, DOI: 10.1021/ar900190f.

[12] A. W. R. Bevan, "Meteorites", in: F. M. Howie (Ed.), The Care and Conservation of Geological Material: Minerals, Rocks, Meteorites, and Lunar Finds, Butterworth-Heinemann, Oxford 1992, pp. 85-101.

[13] K. Stahl, K. Nielsen, J. Jiang, B. Lebech, J. C. Hanson, P. Norby, J. van Lanschot, "On the akaganéite crystal structure, phase transformations and possible role in post-excavational corrosion of iron artifacts", Corrosion Science 45 (2003) 2563-2575, DOI: 10.1016/S0010-938X(03)00078-7. 
[14] L. Selwyn, Metals and Corrosion: A Handbook for the Conservation Professional, Canadian Conservation Institute, Ottawa 2004.

[15] J. E. Post and V. F. Buchwald, "Crystal structure refinement of akaganéite", American Mineralogist 76 (1991) 272-277, DOI: 0003-004X/91/0102$0272 \$ 02.00$.

[16] J. Scheck, T. Lemke, D. Gebauer, “The Role of Chloride Ions During the Formation of Akaganeite Revisited", Minerals 5 (2015) 778-787, DOI: 10.3390/ $\min 5040524$.

[17] V. F. Buchwald and R. S. Clarke, Jr., "Corrosion of $\mathrm{Fe}-\mathrm{Ni}$ Alloys by $\mathrm{Cl}$-Containing Akaganéite $(\beta-\mathrm{FeOOH})$ : The Antarctic Meteorite Case", American Mineralogist 74 (1989) 656-667, http://rruff. info/doclib/am/vol74/AM74_656.pdf (accessed 8.07.2017).

[18] D. A. Scott and G. Eggert, Iron and Steel in Art: Corrosion, Colorants, and Conservation, Archetype Publications, London 2009.

[19] A. Sjøgren and V. F. Buchwald, "Hydrogen plasma reactions in a D.C. mode for the conservation of iron meteorites and antiquities", Studies in Conservation 36 (1991) 161-171, DOI: 10.2307/1506422.
[20] I. Kotzamanidi, E. Sarris, P. Vassiliou, C. Kollia, G. D. Kanias, G. J. Varoufakis, S. E. Filippakis, "Effect of heat treatment in reducing plasma environments on chloride ion removal and corrosion of oxidised steel artefacts", British Corrosion Journal 34 (1999) 285-291, DOI: 10.1179/000705999101500987.

[21] S. R. Sutton, "Thermoluminescence measurements on shock-metamorphosed sandstone and dolomite from Meteor Crater, Arizona, 2. Thermoluminescence age of Meteor Crater", Journal of Geophysical Research 90:B5 (1985) 3690-3700.

[22] B. Dajnowski and A. Dajnowski, "The Use of new laser technology to precisely control the level of stone cleaning", in: Science and Art: A Future for Stone (Proceedings of the $13^{\text {th }}$ International Congress on the Deterioration and Conservation of Stone), Paisley, Scotland, September 6-10, 2016, J. J. Hughes and T. Howind (Eds.), University of the West of Scotland, Paisley 2016, pp. 719-728.

[23] J. A. Kowalik, D. B. Williams, J. I. Goldstein, "Formation of the lamellar structure in Group IA and IIID iron meteorites", in: Lunar and Planetary Science Conference, $18^{\text {th }}$, Houston, TX, Mar. 16-20, 1987, Proceedings, Cambridge University Press/Lunar and Planetary Institute, Cambridge and Houston, TX, 1988, pp. 493-501. 